\title{
INQUÉRITO SOROLÓGICO PARA A DETECÇÃO DE ANTICORPOS CONTRA O VÍRUS DA IMUNODEFICIÊNCIA HUMANA (VIH) EM CRIANÇAS INTERNADAS EM ENFERMARIA GERAL
}

\author{
André Alexandre Osmo* \\ Janete Honda* \\ Evandro Roberto Baldacci* \\ Yassuhiko Okay** \\ Antranik Manissadjian**
}

OSMO, A. A. et. al. Inquérito sorológico para a detecção de anticorpos contra o vírus da Imunodeficiência Humana (VIH) em crianças internadas em enfermaria geral. Rev. Saúde públ., S. Paulo, 24: 113-8, 1990.

RESUMO: São apresentados os resultados de um inquérito sorológico para a detecção de anticorpos contra o Vírus da Imunodeficiência Humana (VIH), em grupo não selecionado de crianças, internadas numa enfermaria geral de pediatria. Foram testados 441 pacientes pelo método ELISA, com uma positividade de $1,1 \%$, cujos resultados foram confirmados pelos testes de Western-Blot e/ou ImunoBlot. $\mathrm{Ne}$ nhum dos cinco pacientes com teste positivo apresentou história de transfusão anterior, enquanto que $4,3 \%$ dos pacientes estudados apresentaram história transfusional. Todas as mães apresentaram também testes ELISA positivos. Em quatro casos, pelo menos um dos genitores referiu uso de drogas por via endovenosa. Em todas as crianças, o modo de transmissão foi vertical. A partir desses achados sugere-se a necessidade de a equipe de saúde tomar precauções quando da manipulação de sangue ou secreçōes. Recomendase a realização de inquéritos anônimos em enfermarias de hospitais gerais para auxiliar na determinação da real prevalência das infecções pelo VIH.

DESCRITORES: Anticorpos anti-HIV, isolamento. Sorodiagnóstico para AIDS.

\section{INTRODUÇÃO}

A definição de caso de Síndrome da Imunodefiência Humana Adquirida (SIDA) na criança sofreu modificaçoes importantes no decorrer dos últimos anos. Inicialmente, baseava-se na existência de imunodeficiência celular inexplicada, com presença obrigatória de infecção oportunista documentada ou de pneumonite intersticial linfóide 2,5, $12,16,23,24$. Estima-se, no entanto, que em decorrência desta definição restritiva ocorreu uma provável subnotificação de casos da ordem de $70 \%$ nos EUA ${ }^{3 \text {, }}$ $16,26,27$.

O desenvolvimento de técnicas de cultivo do VIH em sangue e outros tecidos, bem como de testes altamente sensíveis e específicos para a detecção de anticorpos anti-VIH e, mais recentemente, de técnicas para identificação de antígenos próprios do vírus, ampliaram, sobremaneira, as possibilidades diagnósticas $1,2,6,19,20,21,22,25$.

Paralelamente, a caracterização de algumas situaçōes clínicas associadas à SIDA, e o melhor conhecimento da epidemiologia da doença na criança, levaram o Centro de Controle de Doenças
(CDC), dos EUA, em abril de 1987, a rever e propor um quadro de critérios diagnósticos de SIDA em crianças $1,5,23,26,28$.

Esta classificação, sinteticamente, divide as crianças com menos de 13 anos de idade, com sorologia positiva para o VIH, em três grandes grupos ou classes:

P-0: Infecção indeterminada, isto é, sorologia positiva para VIH por transferência passiva de anticorpos em menores de 15 meses de idade e assintomáticos para a SIDA;

P-1: Infeç̧ão assintomática, isto é, sorologia positiva para VIH por anticorpos próprios (excluída a transferência passiva materna em menores de 15 meses de vida), com função imune normal (subclasse A), anormal (subclasse B) ou não pesquisada (subclasse $\mathrm{C}$ );

P-2: Infecção sintomática, em crianças de qualquer idade, distribuídas nas seguintes subclasses: subclasse A - achados inespecíficos; subclasse B doença neurológica progressiva; subclasse $C$ - pneumonite intersticial linfóide; subclasse D - infecções

\footnotetext{
* Divisão de Pediatria do Hospital Universitário da Universidade de São Paulo - Cidade Universitária - 05508
} - São Paulo, SP Brasil.

* Departamento de Pediatria da Faculdade de Medicina da Universidade de São Paulo - Av. Dr. Arnaldo, 455 01246 - São Paulo, SP - Brasil. 
secundárias; subclasse E - neoplasias secundárias e subclasse F - outras situações associadas à infecção pelo VIH (incluindo dismorfismo crânio-facial). ${ }^{5}$

A partir destes novos critérios, estima-se que o CDC, que até junho de 1988 havia recebido cerca de mil notificações, receberá, até 1991, mais 3.000 notificaçōes ${ }^{23}$.

No Brasil, os dados publicados pelo Ministério da Saúde referem 171 casos notificados em crianças menores de 15 anos de idade, até o final de $1988^{4}$.

A par de todas estas informaçōes, não se possui ainda estimativa fidedigna do número de crianças infectadas pelo $\mathrm{VIH}$, assintomáticas ou com sintomatologia discreta ${ }^{1}$. Por outro lado, para o delineamento de uma estratégia epidemiológica, é essencial o conhecimento da prevalência desta infeçãa. A Academia Americana de Pediatria recomenda a realização de inquéritos sorológicos periódicos e anônimos nos hospitais que integram áreas onde a prevalência da infecção pelo VIH não é conhecida, visando ao esclarecimento da situação. Estes estudos podem ser realizados em amostras da população de crianças internadas, em sangue de cordão umbilical de recém-nascidos, em mulheres em assistência pré-natal ou em adolescentes $^{1}$. A adequação ética destes procedimentos, desde que não impliquem agressão aos pacientes e com o devido conhecimento das autoridades científicas e administrativas locais, estão implícitas nas recomendações do Grupo de Trabatho em AIDS na Criança, da Academia Americana de Pediatria ${ }^{1}$.

Por outro lado, a determinação da prevalência da infecção pelo VIH, na população, adquire grande importância, à medida em que as linhas mestras para o controle da infecção hospitalar em cada área estão na dependência de classificá-la como sendo de alta ou baixa prevalência ${ }^{1}$. As áreas de baixa prevalência, nos EUA da América, têm sido consideradas aquelas com índices de infecção pelo VIH menores de $1.1000^{1}$. Desta definição depende a estratégia que a equipe de saúde deve assumir no cuidado com os pacientes, como o uso ou não rotineiro de luvas para a manipulação de qualquer tipo de doente e os custos administrativos que tal procedimento representa, quando usado desnecessariamente. $O C D C$ sugere que em locais de baixa prevalência (menor que 1.1000), como a probabilidade de contaminação dos profissionais é insignificante (inferior a $1: 10.000 .000$ ), estas medidas adquirem uma relação custo/benefício injustificável, devendo restringirem-se aos pacientes comprovadamente VIH positivos ${ }^{2}$.

A partir destes fatos, os autores desenvolveram um inquérito sorológico para detectar a presença de anticorpos contra o VIH, em crianças internadas nas Enfermarias Pediátricas do Hospital Universitário da Universidade de São Paulo, de dezem- bro de 1987 a fevereiro de 1989. Este hospital atende, predominantemente, a população residente no Distrito do Butantan (São Paulo), com uma população aproximada de 600.000 habitantes, com grande número de pessoas morando em favelas (Vila Dalva, São Remo, Jardim D'Abril, Jaguaré e outras), quase todas nas proximidades do Hospital, que se constitui no principal recurso para internação da região.

\section{MATERIAL E MÉTODO}

De dezembro de 1987 a maio de 1989, foram estudadas 441 crianças escolhidas de forma aleatória dentre as 1.295 internadas, neste período, no Serviço de Pediatria Clínica do Hospital Universitário da USP. Foram estudados apenas os pacientes admitidos para internação no período de 8 às 16 horas, de $2^{\mathrm{a}}$ a $6^{\mathrm{a}}$-feira, devido à facilidade de coleta e encaminhamento do material ao laboratório. Muitas vezes o material para exames sorológicos não foi colhido por descuido ou esquecimento por parte dos internos e residentes do Serviço.

As crianças foram internadas em decorrência de patologias variadas, sem qualquer espécie de seleção.

$\mathrm{Na}$ admissão, os acompanhantes dos pacientes responderam um questionário, com o objetivo de identificar fatores de risco para a infecção pelo VIH. Os pais dos pacientes assinaram, à internação, termo de compromisso, no qual tomavam ciência e se comprometiam a aceitar a realização de exames laboratoriais e procedimentos diagnósticos e terapêuticos que se fizessem necessários para a criança internada.

A amostra de sangue foi colhida o mais precocemente possível e o método utilizado foi o ELISA (enzyme linked immunoadsorbent assay) ${ }^{6,14}$, "kit" do laboratório "Abbott". Os exames foram realizados pela Fundação Hemocentro de São Paulo.

Os casos considerados com sorologia positiva, foram os que apresentaram:

a) Dois testes ELISA positivos;

b) O primeiro teste ELISA inconclusivo e o segundo positivo.

Nenhum paciente apresentou um teste positivo e o outro negativo. Todos os casos positivos realizaram, posteriormente, os seguintes exames: Western-Blot ${ }^{6,14}$ ou Immunoblot ${ }^{14,19}$, relação do número de linfócitos T4:T8 14, 23, 27, dosagem de imunoglobulinas $14,23,27$, além de hemograma e outros exames pertinentes à doença que motivou a internação.

Em todos os casos positivos, reconvocamos os familiares que foram informados da situação e de 
quem solocitamos também a realização do teste ELISA; concomitantemente, foram novamente submetidos ao questionário inicial para a identificação de fatores de risco.

\section{RESULTADOS}

Das 441 crianças que realizaram o teste sorológico para a detecção de anticorpos contra o VIH, este foi positivo em 5 pacientes, caracterizando uma prevalência de $1,1 \%$ de positividade neste grupo de pacientes internados, segundo os critérios anteriormente estabelecidos.

Dos 5 casos positivos, 2 apresentavam idade superior a 15 meses ( 18 e 24 meses) e 3, idade igual ou inferior a 3 meses ( 21 dias, 45 dias e 3 meses). A classificação destes casos e o quadro clínico são mostrados na Tabela 1.

Devemos ressaltar que o caso 2 é compatível com a descrição de SIDA congênita proposta por Feikind e col. ${ }^{10}$, Iosub e col. ${ }^{13}$ e Marion e col. ${ }^{17}$, 18 . A paciente apresentava microcefalia acentuada, fronte proeminente, obliqüidade dos olhos e ponte nasal reta. Todas as pesquisas para outras infecções congênitas (lues, toxoplasmose e citomegalovirose) resultaram negativas. A dificuldade de ganhar peso e as infecçōes recorrentes foram evidências marcantes nessa paciente.

O quadro laboratorial encontrado nos 5 pacientes pode ser apreciado na Tabela 2.

\section{TABELA 2}

Quadro laboratorial dos cinco pacientes com sorologia positiva para anticorpos contra o VIH, internados no Hospital Úniversitário da USP.

\begin{tabular}{|c|c|c|c|c|c|}
\hline \multicolumn{2}{|c|}{$\begin{array}{l}\text { Dados } \\
\text { laboratoriais } \\
\text { Linfopenia } \\
\text { Caso }\end{array}$} & \multirow{2}{*}{$\begin{array}{l}\text { Western } \\
\text {-Blot } \\
+\end{array}$} & \multirow{2}{*}{$\begin{array}{c}\text { Imunoblot } \\
\text { NR }\end{array}$} & \multirow{2}{*}{$\begin{array}{c}\text { Hipergama- } \\
\text { globulinemia } \\
+\end{array}$} & \multirow{2}{*}{$\begin{array}{r}\text { Relação } \\
\text { T4:T8* } \\
0,4\end{array}$} \\
\hline 1 & ausente & & & & \\
\hline 2 & ausente & + & NR & + & 1,8 \\
\hline 3 & ausente & NR & + & NR & NR \\
\hline 4 & ausente & + & + & + & 1,0 \\
\hline 5 & ausente & NR & + & + & 0,6 \\
\hline
\end{tabular}

\section{TABELA 3}

Fatores de risco e resultado do teste de ELISA para a detecçăo de anticorpos contra o VIH nos pais dos pacientes com sorologia positiva, internados no Hospital Universitário da USP.

\begin{tabular}{cccccc}
\hline & \multicolumn{2}{c}{ ELISA } & \multicolumn{2}{c}{ Uso de Tóxicos } & \multicolumn{2}{c}{$\begin{array}{c}\text { Contato da mãe } \\
\text { can }\end{array}$} \\
& Pai & Mãe & Pai & Mãe & vários parceiros \\
\hline $\operatorname{css} 1$ & $*$ & + & + & nega & + \\
$\operatorname{cso} 2$ & $*$ & + & + & nega & + \\
$\operatorname{caso} 3$ & $*$ & + & + & nega & + \\
$\operatorname{css} 4$ & recusou & + & nega & + & + \\
$\operatorname{caso} 5$ & + & + & nega & nega & nega \\
\hline
\end{tabular}

* Pai não mora mais com a familia.

TABELA 1

Classificação e quadro clínico dos pacientes com sorologia positiva para VIH, internados no Hospital Universitário da USP.

\begin{tabular}{|c|c|c|c|c|}
\hline Caso & Idade & Quadro dínico & $\begin{array}{c}\text { Classificação } \\
\text { CDC (4) }\end{array}$ & Evolự̆o \\
\hline 1 & 24 meses & $\begin{array}{l}\text { Pneumonite intersticial linfóide } \\
\text { Diarréia crônica } \\
\text { Neuropatia } \\
\text { Infecçốes repetidas }\end{array}$ & $p-2$ & Óbito \\
\hline 2 & 3 meses & $\begin{array}{l}\text { Dismorfismo crâneo-facial } \\
\text { Deficiência ponderal } \\
\text { Infecçzes repetidas } \\
\text { Hépato-esplenomegalia }\end{array}$ & $\mathrm{p}-2$ & Óbito \\
\hline 3 & 21 dias & Indeterminado & $\mathrm{p}-0$ & Vivo \\
\hline 4 & 18 meses & $\begin{array}{l}\text { Plaquetopenia } \\
\text { Anemia } \\
\text { Hépato-esplenomegalia }\end{array}$ & $\mathrm{p}-2$ & Vivo \\
\hline 5 & 45 dias & $\begin{array}{l}\text { Infecções repetidas } \\
\text { Monilíase persistente } \\
\text { Pneumonite intersticial linfóide } \\
\text { Plaquetopenia } \\
\text { Hépato-esplenomegalia }\end{array}$ & $\mathrm{p}-2$ & Óbito \\
\hline
\end{tabular}


Com relação aos antecedentes epidemiológicos e fatores de risco (Tabela 3), observamos, em 4 dos 5 casos positivos, que pelo menos um dos pais pertencia a grupo de risco. Nenhum dos casos positivos apresentou história transfusional anterior. Dezenove pacientes dentre os 441 (4.1\%) referiram ter recebido pelo menos uma transfusão sangüínea.

\section{DISCUSSÃO}

A realização de inquéritos sorológicos para a detecção de infecção pelo VIH, em crianças internadas e oriundas de áreas nas quais não se conhece a prevalência desta infecção, foi sugerida no relatório do Grupo de Trabalho de SIDA da Academia Americana de Pediatria ${ }^{1}$. Não encontramos, na literatura, referência de pesquisa semelhante na cidade de São Paulo.

A sensibilidade e especificidade dos "kits" comercialmente disponíveis para a realização do teste ELISA com o objetivo de detectar anticorpos contra o VIH tem sido considerada muito boa quando comparada com o teste Western-Blot, utilizado com o "gold standard". A sensibilidade encontrada em vários estudos variou de' 98,1 a $100 \% 3,6,8,11,14$, 20 , embora o valor preditivo dependa da prevalência da infecção por este vírus no grupo populacional em estudo. $O$ valor preditivo de seis diferentes "kits" de ELISA foi de $100 \%$ em pacientes com SIDA, mas variou de 5 a $100 \%$ no grupo de doadores de sangue ${ }^{24}$. Em outro estudo, o valor preditivo negativo variou de $100,0 \%$ na população geral a $76,9 \%$ nos membros de grupos de risco ${ }^{24,30}$.

Nas crianças, principalmente naquelas menores de 15 meses de idade, o resultado dos testes que pesquisam imunoglobulinas da classe Ig $G$ contra o vírus deve ser analisado com cuidado, uma vez que, quando positivo, pode representar, tão somente, transferência passiva das mesmas durante a gestação $1,14,15,23,27,29$.

São também descritos casos com resultado de teste falso negativo, principalmente em situações de hipogamaglobulinemia severa e naqueles casos nos quais o teste foi realizado em um período de tempo no qual coexistem, na criança, a redução dos níveis séricos dos anticorpos maternos, transferidos passivamente, e os anticorpos próprios da criança, ainda em níveis não detectáveis pelos métodos usuais $7,9,10,11,23,27$.
Baseando-nos nestas evidências, optamos pela realização de pelo menos 2 testes ELISA nos pacientes cujo primeiro resultado foi positivo ou inconclusivo e, desde que confirmada a positividade, os submetemos a nova confirmação através dos testes de Western-Blot ou ImunoBlot e provas imunológicas. Comparamos os dados obtidos nas crianças com os dados obtidos nos pais, desde que consentissem a se submeter à realização de provas laboratoriais. Em 4 dos 5 pacientes, pelo menos um dos genitores referiu uso de tóxicos por via endovenosa. Dessa forma, em todos os casos configurou-se a transmissão do tipo vertical, não havendo antecedentes transfusionais.

Os percentuais de positividade que obtivemos foram muito elevados $(1,1 \%)$ em termos de prevalência, para crianças internadas em enfermaria geral de pediatria, devendo-se, porém, levar em conta, que a amostragem é ainda reduzida (441 casos pesquisados). Esta cifra motivou a presente comunicação, com o objetivo de alertar os elementos das equipes de saúde das enfermarias de pediatria para os cuidados, principalmente na manipulação de sangue e secreçōes de qualquer paciente internado. Conforme orientação proposta pela Academia Americana de Pediatria, nas regiões de alta prevalência da doença, deve-se considerar todos os pacientes como potencialmente infectados pelo VIH ${ }^{1}$.

Esclarece-se que o Hospital Universitário da USP tem características assistenciais regionalizadas sendo aproximadamente $60 \%$ do seu atendimento composto por pacientes oriundos do Distrito de Butantan e $40 \%$ de pacientes de outras regiōes, principalmente Osasco, Carapicuíba, Barueri, Itapevi, Jandira e Taboão da Serra. Na área do Butantan, uma parcela significativa da população mora em favelas que praticamente cercam o campus da Universidade de São Paulo. As condições precárias de vida e habitação favorecem a convivência promíscua e constituem, com freqüência, locais de livre trânsito de drogas. Os pacientes com sorologia positiva, que foram internados neste período, eram todos oriundos da região do Butantan.

\section{AGRADECIMENTOS}

Ao Laboratório Fleury de Análises Clínicas e à Fundação Hemocentro do Estado de São Paulo que colaboraram na realização deste estudo. 
OSMO, A. A. et al. [A serological inquiry for the detection of antibodies against the Human Immunodeficiency Virus (HIV) in children in a general ward]. Rev. Saúde públ., S. Paulo, 24: 113-8, 1990.

ABSTRACT: The results of a serum inquiry for detection of antibodies against the Human Immunodeficiency Virus in a non selected group of children, patients of a general pediatric ward, are reported. Of the 441 cases, the ELISA test gave a positive result for $1.1 \%$ of them. This result was confirmed by the Western-Blot or ImmunoBlot test. None of the five children who tested positive had a previous history of blood transfusion. These children's mothers showed positive results to the ELISA test. Of four cases, at least one of the parents was IV drug addicted. In every case the transmission was vertical. On the basis of these findings, it is suggested that hospital staff should take the necessary precautions when manipulating blood and secretions and it is recommended that serum inquiries be made on the wards of general hospitals in the attempt to establish reliable data on the prevalence of HIV.

KEYWORDS: HIV antibodies, isolation. AIDS serodiagnosis.

\section{REFERÊNCIAS BIBLIOGRÁFICAS}

1. AMERICAN ACADEMY OF PEDIATRICS. Task Force on Pediatric AIDS. Pediatric guidlines for infection control of human immunodeficiency virus in hospitals, medical offices, schools and other settings. Pe. diatrics, 82: 801-7, 1988.

2. AMERICAN COLLEGE OF PHYSICIANS. The Acquired Immunodeficiency Syndrome (AIDS) and infection with the Human Immunodeficiency Virus (HIV). Ann. int. Med., 108: 460-9, 1988.

3. ANDERSON, K. C.; GORGONE, B. C.; MARLINK, R. G. Transfusion acquired human immunodeficiency virus infection among immunocompromised persons. Ann. int. Med., 105: 519-27, 1986.

4. BOLETIM EPIDEMIOLÓGICO. AIDS. (Ministério da Saúde). Brasília, 2(5), 1988.

5. CENTERS FOR DISEASE CONTROL. Classification system for Human Immunodeficiency Virus (HIV) infection in children under 13 years of age. Morb. Mort. wkly Rep., 36: 225-30, 1987.

6. CENTERS FOR DISEASE CONTROL. Update: serologic testing for antibody to Human Immunodeficiency Virus. Morb. Mort. wkly Rep., 36: 832-41, 1988.

7. COWAN, J. M.; HELLMAN, D.; CHUDWIN, D.; WARA, D. W.; CHANG, R. S.; AMMANN, A. J. Maternal transmission of Acquired Immunodeficiency Syndrome. Pediatrics, 78: 383-7, 1984.

8. ESTEBAN, J. I.; TAI, C. C.; KAY, J. W. D.; SHIH, J. W.; BODNER, A. J.; ALTER, H. J. Importance of WestemBlot analysis in predicting infectivity of anti-HTLV-III positive blood. Lancet, 2: 1083-6, 1985.

9. FRIEDLAND, G. H. \& KLEDN, R. S. Transmission of Human Immunodeficiency Virus. New Engl. J. Med., 317: 1125-35, 1987.

10.FEIKIND, L. \& MINKOFF, H. L. HIV in pregnancy. Clin. Perinat., 15: 189-99, 1988.

11.GPETZ, D. W.; HALL, S. E.; HARBISON, R. W.; REID, M. J. Pediatric Acquired Immunodeficiency Syndrome with negative immunodeficiency virus antibody response by enzyme-linked immonosorbent assay and Westem-Blot. Pediatrics, 8: 356-9, 1988.
12. GROSSMAN, M. Children with AIDS. Infect. Dis. clin. N. Amer., 2: 533-41, 1988.

13.IOSUB, S.; BANJ, M.; STONE, R. K.; GRANISH, D. S.; WASSERMAN, E. More on immunodeficiency virus embriopathy. Pediatrics, 80: 512-6, 1987.

14.JACKSON, J. B. \& BALFOUR, H. H. Practical diagnostic testing for Human Immunodeficiency Virus. Clin. Microb. Rev., 1(1): 124-38, 1988.

15.KAMANI, N.; LIGHTMAN, H.; LEIDERMAN, I.; KRILOV, L. R. Pediatric Acquired Immunodeficiency Syndrome related complex: clinical and immunologic features. Ped. infect. Dis. J., 7: 383-8, 1988.

16.LEPAGE, P; BATUNGWANAYO, J.; VANDE-PIERRE, P. Seronegativity and HIV infection. Arch. Dis. Child., 64: 135-7, 1989.

17.MARION, R. W.; WIZNIA, A. A.; HUTCHEON, R. G.; RUBINSTEIN, A. Human T-cell lymphotropic virus type III embryopathy. Amer. J. Dis. Child., 140: $638-40,1986$.

18.MARION, R. W.; WIZNIA, A. A.; HUTCHEON, R. G.; RUBINSTEIN, A. Fetal AIDS syndrome score. Amer. J. Dis. Child, 141: 429-31, 1989.

19.MOTZ, M.; BAUER, E. S.; FROSNER, G. G.; GURTLER, L.; SCHALL, M.; WOLF, H. Immunoblot test with recombinant HIV antigens. Lancet, 2: 1093-4, 1987.

20. OLDHAM, L. J.; MOULSDALE, H. J.; MORTIMER, P. P.; TEDDER, R. S.; MORGAN-CAPNER, P. How sensitive are the commercial assays for anti-HTLV-III/ LAV? J. med. Virol., 21: 75-9, 1987.

21.PAWA, S. Human immunodeficiency virus infection in children: nature of the immunodeficiency, clinical spectrum and management. Ped. infect. Dis. J., 7: S61-S71, 1988.

22.PAWA, S.; KAPLAN, M.; FIKRIG, S.; PAWA, R.; SARNGADHARAN, M. G.; POPOVIC, M.; GALLO, R. C. Spectrum of human T-Cell lymphotopic virus type-III infection in children. J. Amer. med. Ass., 255: 2299-305, 1986. 
23. PIZZO, P. A.; EDDY, J.; FALOON, J. Acquired Immunodeficiency Syndrome in children. Amer. J. Med., 85: $195-202,1988$.

24.PRINCIPI, N.; MARCHISIO, P.; MASSIRONI, E.; MONFORTE, A. D.; NOVATI, R.; MORONI, M. Problems of classification of Human Immunodeficiency Virus in seropositive pediatric patients. Ped. infect. Dis. J., 7: 466-8, 1988.

25.REESINK, H. W.; LEILE, P. N.; HUISMAN, J. G.; SCHAASBERG, W.; GONSALVES, M.; AAIJ, C.; WINKEL, I. N.; VAN DER DOES, J. A.; HEKKER, A. C.; DEMYSTER, J. Evaluation of six enzyme immunoassays for antibody against Human Immunodeficiency Virus. Lancet, 2: 483-6, 1986.

26. ROGERS, M. F.; THOMAS, P. A.; STARCHER, E. T.; NOA, M. C.; BUSH, T. J.; JAFFE, H. W. Acquired Immunodeficiency Syndrome in children: report of the Centers for Disease Control National Surveillance, 1982 to 1985. Pediatrics, 79: 1008-14, 1987.
27.RUBDNSTEDN, A. \& BERNSTEIN, L. The epidemiology of pediatric Acquired Immunodeficiency Syndrome. Clin. Immunol. Immunopathol., 40: 115-21, 1986.

28.SAMPAIO, M. M. S. C.; VIEIRA, H. M. C. S.; PORTO, M. H. O.; GRUMACH, A. S.; MARQUES, H. M. S.; YAMAMOTO, M.; DUARTE, A. J. S.; BARBIERI, D.; OSELKA, G. W. Síndrome da Imunodeficiência Adquirida em crianças: relato de 12 casos. J. Pediat., Rio de Janeiro, 64: 211-8, 1988.

29.SHANNON, K. M. \& AMMANN, A. J. Acquired Immunodeficiency Syndrome in childhood. J. Pediat., St. Louis, 106: 332-42, 1985.

30.SIVAC, S.L. \& WORMSER, G.P. Predictive value of a screening test for antibodies to HTLV-III. Amer. $J$. Pathol., 85: 700-3, 1986.

Recebido para publicaçăo em $2 / 811989$

Reapresentado em 8/1190 Aprovado para publicaçáo em 15/1/90 